\title{
Significado político do MobilizaSUS na Bahia nos óculos de Gramsci, pela lente da reforma sanitária brasileira
}

Tiago Parada Costa Silva(a)

Carmen Fontes de Souza Teixeira ${ }^{(b)}$

Silva TPC, Teixeira CFS. The political meanings of MobilizaSUS through the eyes of Gramsci and the lens of Brazilian sanitary reform. Interface (Botucatu). 2014; 18 Supl 2:1283-1298.

Considering the experience of the MobilizaSUS project in Bahia in the debate regarding the limits and possibilities of the participation of the population in health services, the purpose of this presentation is to discuss the political significance of the development of this project. This discussion emerged in the light of the Brazilian Sanitary Reform, and was articulated based on Gramscian categories. We can infer that MobilizaSUS project has features that allowed it to be put side by side with the counter-hegemony in the health sector. However, there are limits to assurance of MobilizaSUS as a counter-hegemonic project, which are mainly related to its institutional origin, which was more closely related to the idea of representing the pores of the superstructure, which are permeable to counterhegemony, due to the method used to articulate subjects of antithesis.

Keywords: Health policies. Social participation. Social change.
Considerando a experiência do projeto MobilizaSUS na Bahia no debate acercados limites e possibilidades da participação popular em saúde, definimos como objetivo discutir o significado político do seu desenvolvimento. Essa discussão se deu à luz da Reforma Sanitária Brasileira, articulada a partir de categorias gramscianas. Podemos inferir que o projeto MobilizaSUS possui características que permitiriam colocá-lo no "lado" da contra-hegemonia no setor saúde. Entretanto, há limites para sua afirmação enquanto projeto contra-hegemônico, relacionados principalmente a sua origem institucional, aproximando-se mais da ideia de representar poros na superestrutura permeáveis à contra-hegemonia, em função de seu método para articular sujeitos da antítese numa práxis histórica na Bahia.

Palavras-chave: Políticas de saúde. Participação social. Mudança social.

\footnotetext{
(a) Secretaria da Saúde do Estado da Bahia, Superintendência de Recursos Humanos, Diretoria de Gestão do Trabalho na Saúde. Rua Bombeiro Eliezer de Alexandrino, no 144, Cond. Residencial dos Coqueiros, bl. C, apto. 202, Bairro Boca do Rio. Salvador, BA, Brasil. 45710-790.tgparada@ yahoo.com.br (b) Bacharelado Interdisciplinar em Saúde, Instituto de Humanidades, Artes e Ciências, Universidade Federal da Bahia. Salvador, BA, Brasil. carment@ufba.br
} 


\section{Introdução}

A Reforma Sanitária Brasileira (RSB) proporcionou a legitimação de uma práxis contra-hegemônica no âmbito das políticas de saúde, no que concerne à participação social. O Sistema Único de Saúde (SUS), com a institucionalização de fóruns colegiados enquanto instâncias decisórias na gestão pública da saúde, desenha um novo cenário em torno do tema da Participação e Controle Social em Saúde (PCSS) e suas questões correlatas, como democracia, poder e relação Estado-sociedade.

Esse tema é motivador de enorme debate, desde a academia até os órgãos responsáveis pela formulação e implementação de políticas de saúde. Assim sendo, o debate crítico a respeito das experiências que vêm se desenvolvendo em torno da PCSS tem importante valor para que o SUS represente o anseio da RSB: o "deslocamento do poder político em direção às camadas populares"1.

Inicialmente há de se considerar que importantes avanços rumo à democratização da saúde vêm ocorrendo a partir das conquistas institucionais do SUS. Para Carvalho²,

um dos feitos mais notáveis da Reforma Sanitária no Brasil foi a institucionalização, no interior do aparelho estatal, de um formidável sistema nacional de órgãos colegiados, dotados de um conjunto razoável de poderes legais e onde os usuários têm representação paritária em relação aos prestadores e ao governo² (p. 93).

A proliferação desses colegiados e fóruns participativos (conselhos e conferências de saúde) tem proporcionado uma importante contribuição para a produção de conhecimento e para a qualificação do debate a respeito do assunto ${ }^{2,3,4,5,6,7}$. Partindo da contribuição de Amélia Cohn ${ }^{8}$, 0 que nos é questionado é

até que ponto e em que sentido essa modalidade de participação de distintos segmentos organizados da sociedade nessas instâncias efetivamente avançam no processo de "democratização da democracia" [...], ou reforçam a presença da dimensão privada e particularista no processo de formulação das políticas de saúde dados os diferentes interesses aí presentes ${ }^{8}$ (p. 17).

Assim sendo, avançar na perspectiva da PCSS exige o aprofundamento do debate teórico, para o aprimoramento do olhar crítico sobre o desenvolver dessa temática no SUS.

Atualmente, há outros marcos institucionais importantes nessa área, além da instituição dos conselhos e conferências, e, nesse sentido, destacamos nacionalmente:

a criação da Secretaria de Gestão Estratégica e Participativa (SGEP), que reúne ações das áreas de gestão participativa, equidade, Educação Popular, ouvidoria, auditoria e monitoramento e avaliação9;

- a Política Nacional de Gestão Estratégica e Participativa no SUS: ParticipaSUS ${ }^{10}$;

- as Diretrizes Operacionais do Pacto pela Saúde, que contempla o Pacto firmado entre os gestores do SUS, em suas três dimensões: Pacto pela Vida, em Defesa do SUS e de Gestão;

- a Política Nacional de Educação Permanente para o Controle Social no SUS, aprovada no Conselho Nacional de Saúde ${ }^{11}$;

- a instituição do Comitê Nacional de Educação Popular em Saúde (CNEPS) ${ }^{12}$ e a formulação da Política Nacional de Educação Popular em Saúde no SUS aprovada no CNS em $2012^{13}$.

- Além desses, há de se considerar, recentemente, o Decreto Presidencial no 7.508/2011, a Lei Complementar no 141/2012, a Resolução do CNS n 453 de 10 de maio de 2012, que ratificam a competência dos conselhos de Saúde na formulação e no controle público da execução da política de saúde, além da Lei de Acesso à Informação, nº 12.527/2011, que regula o acesso à informação pública.

Esses marcos nacionais, como evidências do desenvolvimento da temática da PCSS no SUS, influenciam e são influenciados pelas experimentações que acontecem em outros níveis da federação, como estados e municípios. 
Na Bahia, o rearranjo das forças políticas no âmbito estadual, nas eleições de $2006^{(c)}$, conduziu ao governo um conjunto de atores institucionalmente comprometidos com o desenvolvimento de uma gestão participativa. Nessa conjuntura, dá-se a reinserção daquela temática no Plano Estadual de Saúde PES 2008-2011 14 -, evidenciada no primeiro objetivo do primeiro compromisso de gestão, com um escopo de ações mais amplo que o que consta na Agenda Estadual de Saúde de $2004^{15}$. E com esse contexto é desenvolvido um projeto denominado "MobilizaSUS: estratégias para o fortalecimento do controle social e gestão democrática e participativa e no SUS-Ba"16.

Esse projeto se constitui enquanto uma das ações estratégicas do PES 20082011 para o compromisso de instituir uma "Gestão estratégica, participativa e efetiva do SUS-Bahia"14, tendo como objetivo:

Promover o fortalecimento do Controle Social no SUS, desenvolvendo processos pedagógicos que contribuam para a ampliação e qualificação da participação da população na formulação, gestão e controle social das políticas de saúde ${ }^{16}(p .1)$.

Considerando sua vinculação com o debate acerca dos limites e possibilidades da participação social em saúde contribuir para o processo de democratização do Estado, esse projeto se constitui numa experiência que demanda um olhar crítico.

Dessa forma, definimos como objetivo desta produção discutir teoricamente o significado político do desenvolvimento do MobilizaSUS na Bahia. Essa discussão se deu a luz da RSB, articulada a partir das categorias gramscianas relacionadas ao conceito de hegemonia (sociedade civil, bloco histórico, intelectuais orgânicos), visando contribuir para uma análise do projeto diante da conjuntura em que está inserido, permitindo um debate crítico de seus limites e potencialidades.

Esse é um dos produtos, revisado e atualizado, de um estudo mais amplo, concluído em 2010, sobre "a emergência, desenvolvimento e contradições do cotidiano institucional do MobilizaSUS", que partiu da necessidade de se organizar um desenho avaliativo do projeto baiano, propondo-se a construir um "objeto-modelo" desse projeto e a discussão necessária à constituição de sua teoria, para uma avaliação ${ }^{18}$.

\section{Hegemonia: construindo um referencial}

O conceito de hegemonia em Gramsci é construído a partir de sua concepção do Estado, enquanto "Estado ampliado"(d), bem como sua relação com a "sociedade civil", destacando-se o conceito de "bloco histórico", com o qual Gramsci trata de identificar "a unidade dialética entre forças produtivas, relações sociais de produção e superestrutura jurídico-política num dado momento histórico"19 (p. 137).

A princípio, é preciso resgatar alguns pontos importantes a respeito da teoria marxista para o Estado. Para Marx, o conjunto das relações de produção constitui a estrutura econômica da sociedade, que vai determinar uma superestrutura jurídica e política, o Estado ${ }^{20}$. Segundo Gruppi, apesar de não elaborar a teoria do Estado, Marx forneceu a teoria fundamental para se construí-la, qual seja: "a estrutura econômica está na base do próprio Estado. Esse é o fundamento de onde devemos partir" 20 (p. 28).

Analisando as contribuições de Engels a respeito da origem do Estado, o mesmo autor coloca que este "torna-se uma necessidade a partir de um determinado grau de desenvolvimento econômico, que é necessariamente ligado à divisão da sociedade em classes" 20 (p. 30).

\footnotetext{
(c) De acordo com análises de Dantas Neto ${ }^{17}$, três fatores contribuíram para a eleição do Partido dos Trabalhadores para o governo do estado: o amadurecimento de uma aliança política que conectou o PT à quase totalidade da então oposição baiana, tendo evidência a aliança com o PMDB e a convergência de 11 partidos políticos; a influência do fator nacional, desde apoio pessoal da Presidência da República, influência dos programas e políticas públicas federais,

até a ocupação, por aliados políticos, de cargos federais que intermediavam a relação com os municípios no estado; e o desgaste do grupo que se mantinha há 16 anos no poder em contexto de competição democrática no país.

Segundo o autor, com esse resultado, grupos políticos adversários do carlismo passaram a ser situação na política estadual 17 .

(d) "Estado = sociedade política + sociedade civil, ou seja, hegemonia couraçada de coerção" 19 (p. 177).
} 
A origem das classes sociais estaria na diferenciação da posição dos homens nas relações de produção, que originaria a luta de classes, e, por conseguinte, para que essa luta não se torne dilacerante, a necessidade do Estado. O Estado, então, nasceria da necessidade de refrear os antagonismos de classe, forma pela qual a "classe que detém a propriedade dos principais meios de produção deve institucionalizar sua dominação econômica" 20 (p. 30) e dessa forma, nascendo em meio ao conflito, "é, via de regra, o Estado da classe mais poderosa"20 (p. 30).

Isso posto, percebe-se que, na origem da teoria marxista, o Estado (sociedade política) aparece organicamente vinculado à sociedade civil, estando essas sociedades encerradas nos momentos da superestrutura (sociedade política) e da estrutura (sociedade civil). A ampliação proposta por Gramsci está justamente na adição da sociedade civil ao momento da superestrutura.

De acordo com Bianchi ${ }^{19}$, para Gramsci, sociedade política seria "o Estado no sentido restrito, ou seja, o aparelho governamental encarregado da administração direta e do exercício legal da coerção sobre aqueles que não consentem nem ativa nem passivamente"19 (p. 177). Segundo a interpretação de Portelli21, a sociedade política agrupa o conjunto de atividades que dizem respeito à coerção, ou seja, manutenção, pela força, da ordem estabelecida, mediante o domínio militar e o governo jurídico, força legal, ou o direito.

A sociedade civil, segundo a leitura gramsciana de Bianchi ${ }^{19}$, seria o "espaço da luta de classes e da afirmação de projetos antagônicos"19 (p. 180). Seria o conjunto dos organismos, vulgarmente ditos privados, associado às formas de exercício e afirmação da supremacia de uma classe sobre o conjunto da sociedade ${ }^{19,21}$.

Ainda segundo compreensão de Bianchi ${ }^{19}$ a sociedade política e sociedade civil formam planos superpostos que só se separam para fins analíticos. Essa relação torna possível a análise de um Estado destinado a criar as condições propícias à máxima expansão de um grupo, mas que, para torná-la universal, incorpora à vida estatal reivindicações e interesses dos grupos subalternos ${ }^{19}$. Nessa movimentação, concebem-se as noções de hegemonia e bloco histórico.

Segundo Portelli21, Gramsci estuda a desagregação da hegemonia da classe dirigente pela análise do bloco histórico e a partir daí, como "edifica-se um novo sistema hegemônico e cria-se, pois, um novo bloco histórico"21 (p. 15). Partindo das formulações do autor, é importante afirmarmos a base de classe da hegemonia. A hegemonia se deve a uma classe fundamental e esta o será durante todo o período histórico considerado. Sendo um bloco histórico uma situação histórica determinada, sua análise pode referir-se a uma situação local e historicamente reduzida ou extensa, distinguindose, em referência à hegemonia, três tipos de grupos sociais em seu interior:

por um lado, a classe fundamental que dirige o sistema hegemônico; por outro lado, os grupos auxiliares que servem de base social à hegemonia e de viveiro para seu pessoal; enfim, [...], as classes subalternas(e)21 (p. 99).

Para Gruppi ${ }^{20}$, Gramsci coloca o problema de como se mantém essa coesão, como se obtém esse consenso entre classe fundamental e as demais (por vezes antagônicas). Na leitura do autor, a resposta está na ideologia, "o grande cimento do bloco histórico" 20 (p. 82), e podemos completar com a de Portellii ${ }^{21}$, na qual essa coesão edificada num sistema hegemônico está sob a direção dos intelectuais. Estes seriam a concretização do vínculo orgânico entre estrutura (relações sociais de produção) e superestrutura (Estado) ${ }^{21}$.

Dessa forma, como aponta a interpretação de Portelli ${ }^{21}$, a essencialidade da hegemonia da classe fundamental estaria no seu monopólio intelectual, que, (e) Neste estudo,

essas classes são consideradas como os loci de referência às ações de dominação e coerção na relação com a classe fundamental, que juntamente com as ações de direção e consenso, compõem o sistema hegemônico. 
atraindo os intelectuais de outras camadas, criaria um bloco ideológico, vinculando as camadas de intelectuais aos representantes da classe fundamental.

Seguindo aquela interpretação, os intelectuais formam uma camada social diferenciada, "encarregada de elaborar e gerir a superestrutura que dará a essa classe homogeneidade e direção do bloco histórico" 21 (p. 105).

Os intelectuais não se constituiriam em classe específica, mas em grupos vinculados às diferentes classes. Poderiam exercer diversas funções na superestrutura para contribuir na unidade da classe fundamental e sua hegemonia no bloco histórico, sendo, no nível da difusão da ideologia, "os encarregados de animar e gerir a 'estrutura ideológica' da classe dominante no seio das organizações da sociedade civil [...] e de seu material de difusão" 21 (p. 109). Entretanto, possuiriam certa autonomia em relação a essa classe, "na medida em que não evolui no mesmo nível do bloco histórico" 21.

Nesse sentido, a partir da compreensão de Portelli ${ }^{11}$ sobre a teoria gramsciana, podemos elaborar a relação do bloco ideológico com a classe fundamental a partir das funções/ações de dirigir ou dominar. Ao ser dirigente, para manter a hegemonia, a classe fundamental utiliza o bloco ideológico para "controlar grupos auxiliares, pronta a levar em conta os interesses próprios desses grupos" 21 (p. 90). Ao ser dominadora, a classe fundamental utilizaria o bloco ideológico para "neutralizar as outras classes, abstendose de qualquer compromisso com estas" ${ }^{21}$ (p. 90) e um dos caminhos para isso é o transformismo.

Transformismo seria uma estratégia para decapitar a direção de grupos das classes subalternas, agregando-se seus intelectuais ao redor da classe fundamental. Na leitura de Portelli ${ }^{21}$, o transformismo seria um processo orgânico na coesão da estrutura e superestrutura em um bloco-histórico na medida em que "traduz a política da classe dominante que recusa qualquer compromisso com as classes subalternas e assim atrai seus chefes políticos para agregá-los à sua classe política"21 (p. 87).

Podemos perceber que as ideologias e atividades políticas representam o caminho para os homens tomarem consciência dos conflitos que se desenvolvem no nível da estrutura, o que confere às ideologias e as atividades políticas um valor estrutural, corroborando com a noção de bloco histórico em que "as forças materiais são o conteúdo e as ideologias, a forma" ${ }^{21}$ (p. 56).

Nesse ponto é importante resgatarmos do pensamento gramsciano a relação pedagógica na relação de hegemonia. Segundo compreensão de Bianchi ${ }^{19}$, na passagem do homem singular para a esfera das classes, na esfera política, no processo denominado de catarse, é que se dá a conformação do homem coletivo:

é no nexo existente entre governantes e governados, dirigentes e dirigidos, intelectuais e não intelectuais que se torna possível identificar de modo mais preciso essa relação e o processo de formação de uma "personalidade histórica". ${ }^{19}$ (p. 192)

Discutida essa dinâmica do bloco histórico, é importante que retomemos as condições estruturais da evolução da superestrutura, recuperadas por Gramsci da referência marxista:

[...] uma sociedade não se propõe a nenhuma tarefa para a qual não existam já as condições necessárias e suficientes que estariam, pelo menos, em vias de aparição ou desenvolvimento; e [...] nenhuma sociedade se dissolve nem pode ser substituída enquanto não tiver desenvolvido todas as formas de vida implicitamente contidas em suas relações ${ }^{21}$ (p. 55).

Isso nos permite atentar para a questão das temporalidades dos diferentes momentos do bloco histórico, em que o momento da estrutura é o menos variável, no desenvolvimento histórico, que o da superestrutura. Nesse sentido, Portelli ${ }^{21}$ identifica em Gramsci fenômenos não orgânicos da superestrutura no campo das ideologias e ações políticas, podendo estar relacionados a movimentos conjunturais, reorganização interna, erros políticos da classe dirigente, ou a ideologias arbitrárias sem importância histórica, que não representam mudanças de âmbito estrutural.

Recuperadas as noções de Estado, hegemonia e bloco histórico de Gramsci, para fins desse estudo, faz-se necessário um resgate da experiência política mais significativa para o setor saúde no Brasil, a Reforma Sanitária Brasileira, constituindo-a baliza crítica para o olhar sobre o projeto MobilizaSUS. 


\section{A Reforma Sanitária Brasileira: um passeio "ensaiando"}

A Reforma Sanitária Brasileira - RSB - nasce numa conjuntura de transição democrática, em fins de um período ditatorial que, sob a égide de um suposto milagre econômico, configurava um modelo de privilegiamento do produtor privado na saúde, com financiamento público via sistema previdenciário 22 . Sua origem se torna possível pela aproximação dos debates do campo da saúde e das ciências sociais( ${ }^{(f)}$ com forte influência das teorias marxistas $22,24,25,26,27$. Como aponta Fleury:

A incorporação das análises dos teóricos marxistas contemporâneas a respeito do Estado possibilitou transpor compreensão da política pública para além de seu caráter legitimador, como um espaço na luta pela manutenção da hegemonia ou na consolidação de propostas contra-hegemônicas e formação de um novo bloco histórico. ${ }^{24}$ (p. 22)

A assunção da leitura marxista para o campo da saúde pode ser evidenciada no conceito de saúde formulado durante a $8^{\text {a }}$ Conferência Nacional de Saúde (marco político relevante na implementação dessa reforma):

Em seu sentido mais abrangente, a saúde é a resultante das condições de alimentação, habitação, educação, renda, meio ambiente, trabalho, transporte, emprego, lazer, liberdade, acesso e posse da terra e acesso a serviços de saúde. É, assim, antes de tudo, o resultado das formas de organização social da produção, as quais podem gerar grandes desigualdades nos níveis de vida. A saúde não é um conceito abstrato.

Define-se no contexto histórico de determinada sociedade e num dado momento de seu desenvolvimento, devendo ser conquistada pela população em suas lutas cotidianas ${ }^{28}$ (p. 4).

Os marcos teóricos que vão nortear essa reforma são originários do seio dos aparelhos ideológicos do Estado (os departamentos de Medicina Preventiva das universidades), tendo como maior intelectual, Antonio Sérgio Arouca com sua histórica tese de doutorado intitulada: "O dilema preventivista: contribuições para a compreensão criticada Medicina Preventiva"22,24,27. Para Fleury, Arouca lança as bases teóricas para a organização do movimento sanitário a partir da seguinte análise:

A viabilidade do projeto preventivista implica a superação de seus limites liberais que pretendem redefinir as responsabilidades do médico por meio da inculcação de uma preocupação social, mantendo, no entanto, preservadas a natureza de seu trabalho, a organização da prática médica e a estrutura social. Transcender esses limites restritos à alteração dos comportamentos dos profissionais requer formular uma teoria que dê conta das reais determinações da crise no setor saúde e caminhar em direção a uma prática política que represente um movimento de transformação conjunta do trabalho médico, da consciência sanitária, da produção das condições de saúde e doença, do conhecimento, e das políticas de saúde ${ }^{29}$ (p. 243).

Para a autora, o caráter dual da saúde, enquanto valor universal e núcleo subversivo da estrutura social, representa condições e possibilidades

\footnotetext{
(f) Aproximação esta que se dá nas disputas teórico-ideológicas nas ciências políticas (na qual facilmente se identificam os pólos do liberalismo e do marxismo) que envolviam a relação Estado/sociedade e embalavam as discussões sobre o desenvolvimento de políticas sociais principalmente a partir das experiências socialdemocráticas dos países europeus evidenciadas pelo Welfare State ${ }^{23}$.
} 
para a construção de um bloco histórico, devido a: possibilidade de desenvolvimento da consciência sanitária ao mesmo tempo como consciência de cidadão, já que a incidência da saúde/doença, enquanto processos coletivos e de individualidades, permite no mesmo cidadão a reflexão sobre o corpo produtivo - corpo biológico e o corpo socialmente investido; a convergência de interesses policlassistas, que possibilitaria a criação de amplos arcos de alianças políticas em direção a um projeto globalizante; e a existência de um acervo de conhecimentos que permitiriam a explicação dos fenômenos saúde doença e a transformação efetiva do perfil epidemiológico prevalente da atual organização social da prática médica ${ }^{24}$.

Dessa forma é que, defendendo a bandeira: saúde é democracia, democracia é saúde, ratificando a participação como "item privilegiado do corpo doutrinário e da pauta programática da Reforma Sanitária"2 (p. 95), o movimento sanitário, ou movimento da reforma sanitária, aliou

a eficiente organização política do movimento social com a busca da formulação de um projeto alternativo para o sistema de saúde, alcançando ser, ao início do processo de democratização, um ator político impossível de ser ignorado ${ }^{1}$ (p. 29).

Para Paim"22, o movimento sanitário é considerado "um conjunto articulado de práticas ideológicas, políticas, científicas, teóricas, técnicas e culturais" 22 (p. 34), o que aponta para uma especial ênfase à discussão entre o saber e essa práxis na RSB (criatura do Movimento Sanitário), numa distinção entre proposta e processo, num Estado que possui importantes filtros a projetos reformistas ${ }^{22}$.

Segundo o autor, a RSB é um tema que reúne ambiguidades, em sua definição, e hipóteses concorrentes teórico-conceituais e metodológicas para seu desenvolvimento, por parte de cientistas políticos e os atores e autores do movimento sanitário ${ }^{30}$. Parte ainda do pressuposto da RSB enquanto reforma social, trazendo como proposta analítica o ciclo "ideia-proposta-projetomovimento-processo", em que "esses momentos encontram-se, dialeticamente, imbricados: movimento gera o projeto e desencadeia o processo e este condiciona o próprio movimento" 22 (p. 33).

A partir do referencial teórico da guerra de posições ${ }^{30}$, no desenvolvimento do processo da RSB, há de se observar ambiguidades de orientações, que, para interesse deste estudo, ilustraremos como: "do intraburocrático ao social" ${ }^{31}$ ( $p$. 331); ou perspectiva movimentista ou institucionalista ${ }^{1}$; ou ambivalência entre reforma geral e reforma parcial (ou setorial) ${ }^{22}$.

Neste estudo, consideramos uma ambivalência entre, de um lado, "uma perspectiva de mobilização da comunidade e socialização política"1 (p. 27), que proporcionaria o suporte à ampliação da base de massas na perspectiva de uma reforma geral"22, factível de gerar uma "transformação da vida cotidiana das pessoas" 22 (p. 38), e, de outro,

um processo de transformação da norma legal e do aparelho institucional que regulamenta e se responsabiliza pela proteção à saúde dos cidadãos e corresponde a um efetivo deslocamento do poder político em direção às camadas populares, cuja expressão material se concretiza na busca do direito universal à saúde e na criação de um sistema único sob a égide do $\operatorname{Estado}^{1}$ (p. 28).

Nesse aspecto, a década de 1990, pós-constituinte, é ilustrativa, com importante processo normativo (Leis orgânicas no 8.080/90 e no 8.142/90, 
Normas Operacionais Básicas - NOB), expressando a "pactuação pelo alto" 30 (p. 638) e caracterizando 'um certo 'jeito NOB de fazer o SUS', esculpindo-o a 'golpes de portaria'" 32 (p. 293). Em que pesem as discussões a respeito dos limites dessas normatizações, o processo pode demonstrar a institucionalização de uma potencialidade contra-hegemônica ao possibilitar à oposição as propostas neoliberais hegemonizadas no período(s).

De acordo com os fatos, estudos e debates atualizados por Paim ${ }^{22}$, que ratificam uma inclinação à segunda opção no processo da RSB, reforça-se a tese de que, ante um Estado "capitalista, autoritário, privatizado e patrimonialista" 22 (p. 66), adepto às reformas parciais e ao transformismo, numa constante de transformar conservando e conservar transformando,

a Reforma Sanitária Brasileira reduziu-se a uma reforma parcial, inscrita nas suas dimensões setorial e institucional com a implantação do Sistema Único de Saúde (SUS) ${ }^{22}$ (p. 309).

Entretanto, o autor completa:

[...] esse desfecho atual [...] não exclui, todavia, as possibilidades de seu "núcleo subversivo" e os portadores da antítese empurrarem o seu processo para uma reforma geral ou eventualmente, para uma revolução no modo de vida²2 (p. 309-10). (g) As recomendações das agências financiadoras internacionais na década de 1990 impunham a redução da atuação estatal na regulação da economia ajustando as receitas anticíclicas keynesianas a uma ortodoxia liberal remontada às ideias clássicas de Adam Smith, articulando o trinômio da focalização, privatização e descentralização ${ }^{23}$.

Assim, podemos considerar que a RSB não é um processo finalizado, diante das lacunas evidenciadas no que se refere às promessas de ampliação da consciência sanitária e efetivação do direito à saúde. Há de se considerar que a estratégia hegemonicamente adotada pela RSB até o momento deu conta de proporcionar um contexto interessante e desafiador, com importantes avanços na área de produção de conhecimentos e na legitimação da contra-hegemonia por intermédio da institucionalização do SUS, com potencialidade para construção de um novo bloco histórico.

Atualmente, presenciamos a Saúde Coletiva consolidada enquanto campo científico específico, ao tempo que o Sistema Único de Saúde constitui um novo cenário na guerra de posição, com um importante arcabouço jurídico-institucional pareado a um valoroso acúmulo na gestão da máquina estatal, aprendizado caro ao movimento sanitário, a ponto de se dar margem a jargões do tipo: "o SUS é uma escola!".

Entretanto, para seguir enfrentando a inércia no Estado, consideramos que se faz necessária a revisão de rumos e, talvez, estejamos no tempo de investir "no outro pólo de estratégias", o "movimentista", considerando que "radicalização da democracia implica na ênfase da atuação da sociedade civil para o reforço da contra-hegemonia"22 (p. 321).

\section{MobilizaSUS: limites e potencialidades}

O MobilizaSUS foi formulado em 2008, enquanto produto de seminários regionais ocorridos no ano anterior, que propunham abertura de canal de diálogo com os movimentos populares. Essa formulação se deu a partir de um grupo de trabalho - GT MobilizaSUS -, constituído por representantes da Sesab, de movimentos sociais representados no Conselho Estadual de Saúde - CES -, da Secretaria da Educação do Estado da Bahia - SEC -, do Ministério Público e do Conselho Estadual dos Secretários Municipais de Saúde da Bahia ${ }^{18}$. 
Assumindo a Educação Popular como orientadora do método pedagógico, esse projeto vem sendo desenvolvido

no interior do estado da Bahia por meio de encontros, videoconferências, oficinas, rodas de conversações e exposições dialogadas, debatendo a necessidade de organização política e a proposta de formação de rede para a efetivação do direito à saúde. São trabalhadas metodologias participativas, desenvolvendo-se processos educativos e organizativos que valorizem as diversas experiências no âmbito do SUS e que contribuam para participação mais efetiva da população na formulação, gestão e controle social das políticas de saúde, com a utilização de técnicas de animação de grupo, envolvendo música, arte, expressão corporal, práticas de cuidado, dramatização e sistematização ${ }^{18}$ (p. 32).

Recuperando sua trajetória, podemos afirmar que esse projeto possui, nos diversos âmbitos de atuação institucional, fragilidades e limites relacionados à mobilização de poderes político, administrativo e técnico ${ }^{33}$. Consideramos que esse projeto apresenta como desafio a rediscussão da relação entre a burocracia estatal e a sociedade civil, ao possuir ações que colocam atores institucionais enquanto articuladores das relações entre os movimentos sociais e entre estes e as instituições, para a participação e controle social. Todavia, também podemos identificar uma potência transformadora relacionada principalmente a características do método que o constitui ${ }^{18}$.

Observando as características do MobilizaSUS, com sua intenção subjacente de contribuir para a construção de uma consciência crítica para a participação popular na efetivação do direito à saúde, podemos considerar que há uma afinidade à perspectiva movimentista da RSB. Assim, o debate a respeito do significado político desse projeto para a gestão da saúde na Bahia, num olhar a partir da RSB, passa pela questão: quais os limites e potencialidades do MobilizaSUS enquanto um projeto contra-hegemônico?

Desse ponto, destacamos alguns aspectos para a discussão. O primeiro é, no contexto do estudo, a conotação do Estado baiano de apresentar-se enquanto facilitador para as condições de transformação social ${ }^{33}$, sugerida pela constituição de um projeto contra-hegemônico por dentro dele. A plausibilidade para essa ideia poderia ser atribuída a consequências das conquistas instituintes da RSB, frutos de seu projeto e processos contra-hegemônicos.

Entretanto há de ser observado que o contexto da inserção do MobilizaSUS, na agenda política baiana, ocorre numa situação que, antes de ser considerada uma mudança estrutural nas relações de poder, pode ser enquadrada em um dos fenômenos não orgânicos da superestrutura ${ }^{21}$. Dessa forma, o comprometimento com a institucionalização da gestão participativa do SUS ${ }^{14}$, não incide necessariamente no atual bloco ideológico baiano.

Entretanto, dado seu caráter educativo, o projeto MobilizaSUS pode apresentar uma potencialidade instituinte capaz de fazer frente ao instituído. Essa potencialidade estaria inscrita na reinserção de outros atores na arena da PCSS. Tal reinserção corroboraria com a ideia da construção permanente do sujeito, com poder transformador do instituído em instituinte ${ }^{34}$, o portador da antítese, que empurraria o processo de radicalização da democracia, numa "ênfase da atuação da sociedade civil para o reforço da contra-hegemonia"22 (p. 321).

Então, passemos a discutir os aspectos embutidos no projeto que apontam para a identificação dos sujeitos portadores da antítese e para a compreensão do processo educativo como parte da práxis histórica potencialmente transformadora do bloco ideológico. Podemos considerar que o pensamento gramsciano está voltado para "municiar as organizações das classes subalternas que lutam para conquistar sua liberdade e sua hegemonia" 35 (p. 74). Segundo Semeraro ${ }^{35}$, na "catarse" gramsciana, as novas forças sociais

assumem progressivamente atitudes em contraposição à ideologia dominante até amadurecer uma visão independente e superior de mundo, para a qual convergem os diferentes grupos que lutam pelos mesmos horizontes sociais e políticos ${ }^{35}$ (p. 74). 
Paralelamente, para enfrentar o bloco ideológico baiano, o MobilizaSUS se direcionaria a municiar os movimentos sociais ${ }^{(h)}$ assumindo os princípios da Educação Popular como fundamento. Segundo Gohn ${ }^{37}$, os movimentos sociais "expressam energias de resistência ao velho que os oprime, e fontes revitalizadas para a construção do novo" ${ }^{37}$ (p. 14).

A assunção da Educação Popular enquanto orientadora do método para a catarse agregaria potência para a promoção de cenários nos quais os movimentos sociais poderiam se fazer mais presentes em processos decisórios, apresentando novas temáticas, experiências e desejos ${ }^{38}$. Segundo Vasconcelos ${ }^{39}$, a Educação Popular

busca trabalhar pedagogicamente o homem e os grupos envolvidos no processo de participação popular, fomentando formas coletivas de aprendizado e investigação de modo a promover o crescimento da capacidade de análise crítica sobre a realidade e o aperfeiçoamento das estratégias de luta e enfrentamento. É uma estratégia de construção da participação popular no redirecionamento da vida social ${ }^{39}$ (p. 21).

Dessa forma, assumindo o pensamento gramsciano, podemos sugerir que nesses direcionamentos estariam a potência contra-hegemônica do MobilizaSUS. Desse ponto é importante que retomemos a discussão da relação: burocracia estatal e movimentos sociais.

A burocracia estatal pode representar ao mesmo tempo dois papéis: o de arena de luta política, onde uma série de atores disputam decisões e formulações de políticas, leis, normas etc., e o de ator social, enquanto agente de iniciativas, implementador, interlocutor de outros atores ${ }^{40}$. Além disso, vigoraria uma concepção hegeliana em que a burocracia estatal teria uma função de mediadora entre interesses particulares da sociedade civil e o interesse geral do Estado ${ }^{40}$.

No caso em estudo, podemos considerar a interação dos dois papéis. Assim, podemos afirmar que o MobilizaSUS possui limites no protagonismo da burocracia-ator, de alguma forma experimentados nos desafios cotidianos de seu desenvolvimento, que delineiam a burocracia-arena. Esses limites podem ser representados pela questão pontuada por Lucchesi ${ }^{40}$ :

a (im)possibilidade de uma clara e definitiva delimitação dos seus papéis de sujeito (como ator social) ou de instrumento (funcionando como executores de planos cuja formulação escapa aos seus domínios $)^{40}$ (p. 178).

No outro pólo (movimentos sociais), no âmbito da sociedade civil, encontramos uma ideia de participação cidadã na Bahia, marcada "por uma cultura política regional assentada na reprodução de um Estado patrimonialista autoritário e em relações sociais mediadas por estruturas corporatistas e clientelistas" ${ }^{41}$ (p. 203). Segundo Pinheiro ${ }^{42}$, a história do poder político na Bahia não passa por um projeto político maior, por uma ideia de classe, e sim pelo indivíduo e é com este que o Estado estabelece relação, numa corrida que "conserva o passado, mantém desigualdades estruturais e se fundamenta no exercício do mandato político enquanto sinecura em benefício próprio" ${ }^{41}$ (p. 206).

Além disso, a supressão autoritária do pluralismo em nome de uma modernização conservadora - o "carlismo", atrofiando a sociedade política se associa ao "cimento ideológico que aspira conectar elite e povo" 43 ( $p$. 232), o mito da "baianidade" 41 (p. 207). Tal situação desemboca num quadro (h) A identificação dos movimentos sociais como lócus dos sujeitos portadores da antítese se justificaria pela relação teórica entre esses e as categorias de classe (lócus original em Gramsci), estabelecida por Touraine ${ }^{36}$. 
baiano de descaso popular e apatia política dos cidadãos, discutido nos estudos de Milani ${ }^{41}$. Essa situação permite que ainda hoje nos deparemos com situações que remontam ao que Dantas Neto, referindo-se ao cenário político baiano de 1978, caracterizou como espaço público "surdo e quase mudo"43 (p. 228).

Dessa forma, estaria configurado um paradoxo para MobilizaSUS, ao considerá-lo em si, aprioristicamente, como contra-hegemônico: atores da sociedade política historicamente habituados a fazer calar ou a falar por, propondo-se oportunizar a voz de atores da sociedade civil que estão historicamente habituados a enfrentarem as investidas para serem calados. Uma delicada equação quando se está, como caracterizado por Paim ${ }^{22}$, sob a égide de um Estado adepto ao transformismo.

Assim, podemos inferir que o projeto MobilizaSUS possui características que nos oportunizariam, talvez, retomar o espectro da imagem objetivo da RSB movimentista, enquanto possibilidade para "um efetivo deslocamento do poder político em direção às camadas populares" ${ }^{1}$ (p. 28). Entretanto há limites para sua afirmação enquanto projeto contra-hegemônico, e sua origem institucional claramente o limita nesse sentido.

\section{Para não concluir}

Ante o discutido até aqui, podemos afirmar, embora não de forma conclusiva, que o MobilizaSUS não representa per si uma contra-hegemonia, necessitando, para isso, dos sujeitos portadores da antítese enunciados por Paim ${ }^{22}$, que estão para além dos formuladores e implementadores institucionais do projeto. O que não impede que, numa hipótese otimista, tal projeto possa representar poros na superestrutura permeáveis à contra-hegemonia.

A partir dessa hipótese, trazemos algumas questões que podem ser sistematizadas a partir desse trabalho e contribuir para inspirações a um desenho avaliativo.

Utilizando esquematicamente o Postulado de Coerência de Testa ${ }^{33(i)}$, focando o vértice do método, questionamos em que medida o Mobilizasus está criando condições de espaço, tempo ${ }^{44}$ para poder avançar diante das limitações condicionantes da organização? Avançando para outro nível do postulado, qual seria a "Teoria" do Mobilizasus que, aproveitando a determinação histórica para sua ocorrência, o orientaria para enfrentar a determinação de um suposto Estado em disputa? E, pragmatizando, como proporcionar a apropriação da proposta desse projeto pelos atores portadores da antítese que o emprestarão substância contra-hegemônica: os movimentos sociais?

Não concluindo, mas apontando um possível significado teóricopolítico para a experiência baiana do MobilizaSUS, podemos dizer que seu desenvolvimento se converte numa unidade dialética onde se contrapõe uma considerável potência emancipadora e fatores limitantes (internos e externos à instituição) que podem ser cruéis aos seus objetivos originais, podendo transitar da transformação ao transformismo.

Essa situação dialética não permite conclusão no espaço de um texto, necessitando evidentemente da mediação da práxis, investindo-se na suposição de Paim ${ }^{45}$ de que o que se faz mais necessário é a "articulação de sujeitos sociais" em torno desse "campo científico e âmbitos de práticas [da saúde coletiva], na formulação e condução de políticas consequentes" 45 (p. 151).

\footnotetext{
(i) $\mathrm{O}$ autor propõe uma articulação triangular de relações de condicionamento e determinação, num primeiro nível, entre propósito, método e organização, e, num segundo mais externo e relacionado ao primeiro, entre Papel do Estado, Teoria e História ${ }^{33}$.
} 


\section{Colaboradores}

Tiago Parda Costa Silva participou da elaboração do artigo, redação, revisão bibliográfica, discussões e revisão do texto. Carmen Fontes de Souza Teixeira participou da elaboração do artigo, orientação, revisão bibliográfica, discussões e revisão do texto.

\section{Referências}

1. Fleury SM, organizadora. A questão democrática na saúde. São Paulo: Lemos; 1997. p. 25-44.

2. Carvalho Al. Conselhos de saúde, responsabilidade pública e cidadania: a reforma sanitária como reforma de Estado. In: Fleury SM, organizadora. Saúde e democracia: a luta do CEBES. São Paulo: Lemos; 1997. p. 93-111.

3. Vianna MLTW, Cavalcanti ML, Cabral MP. Participação em saúde: do que estamos falando? [Internet]. Porto Alegre. Sociologias; 2009 [acesso 2014 Mar 5]; (21):218-51. Disponível em: http://www.scielo.br/scielo.php?script=sci_arttext\&pid=S1517-45222009000100010\&lng $=p$ t\&nrm=iso. http://dx.doi.org/10.1590/S1517-45222009000100010.

4. Rocha MND. Produção de conhecimento sobre "participação e controle social em saúde" (1980-2005) [dissertação]. Salvador (BA): Instituto de Saúde Coletiva, Universidade Federal da Bahia; 2008.

5. Labra ME. Existe uma política de participação e controle social no setor saúde? Contribuições para um debate urgente. Texto preparado para o Centro Brasileiro de Estudos de Saúde - CEBES [Internet]. Rio de Janeiro: CEBES; 2007 [acesso 2009 Out 10]. Disponível em: http://cebes.iphotel.info/media/file/participa\% C3\% A7\% C3\% A30\% 20 e\% 20Controle\%20Social\%20no\%20Setor\%20de\%20Sa\% C3\%BAde_Eliana\%20labra.pdf

6. Correia MVC. Controle social na saúde. In: Mota AE, Bravo MIS, Uchoa R, Nogueira V, Marsiglia R, Gomes L, et al., organizadores. Serviço social e saúde: formação e trabalho profissional. São Paulo: OPAS, OMS, Ministério da Saúde; 2006. p. 111-40.

7. Cortes SM. Céticos e esperançosos: perspectivas da literatura sobre participação e governança na área da saúde. In: Pinheiro R, Mattos RA, organizadores. Gestão em redes: práticas de avaliação, formação e participação na saúde. Rio de Janeiro: Cepesc; 2006. p. 401-26.

8. Cohn A. Estado e sociedade e as reconfigurações do direito à saúde. Cienc Saude Colet. 2003; 8(1):9-18.

9. Ministério da Saúde. Secretaria de Gestão Estratégica e Participativa [Internet]. 2009 [acesso 2009 Out 10]. Disponível em: http://portal.saude.gov.br/portal/saude/Gestor/ area.cfm?id_area $=384$.

10. Ministério da Saúde. Secretaria de Gestão Estratégica e Participativa. Política Nacional de Gestão Estratégica e Participativa no SUS - ParticipaSUS. 2a ed. Brasília (DF): Ministério da Saúde; 2009.

11. Ministério da Saúde. Conselho Nacional de Saúde. Política nacional de educação permanente para o controle social no Sistema Único de Saúde - SUS. Brasília (DF): Ministério da Saúde; 2006.

12. Portaria $n^{\circ}$ 1.256, de 17 de junho de 2009. Institui o Comitê Nacional de Educação Popular em Saúde (CNEPS). Diário Oficial da União, Brasília, DF, 18 jun. 2009. Seção I, p. 41, col. 2.

13. Ministério da Saúde. Conselho Nacional de Saúde Reunião Ordinária do Conselho Nacional de Saúde - CNS, n 235. Ata [Internet]. Brasília(DF): Secretaria Executiva do CNS; 2012 [acesso 2013 Mar 10]. Disponível em: http://conselho.saude.gov.br/atas/atas_12.htm

14. Secretaria da Saúde do Estado da Bahia. Plano Estadual de Saúde: gestão 2007- 2010. Rev Baiana Saude Publica. 2009;33 Supl 1:13-87. 
15. Secretaria da Saúde do Estado da Bahia. Superintendência de Planejamento e Monitoramento da Gestão Descentralizada de Saúde. Agenda estadual de saúde - mais saúde com qualidade: reduzindo desigualdades [Internet]. Salvador: SESAB; 2004 [acesso 2013 Nov 3]; 98. Disponível em: http://www2.saude.ba.gov.br/arquivos/AgendaEstrategicaSaude/ AGENDA\% 20ESTADUAL\%20DE\% 20SA\% C3\%9ADE\% 202004.pdf

16. Secretaria da Saúde. Superintendência de Recursos Humanos. Diretoria de gestão do Trabalho e da Educação na Saúde. MobilizaSUS: estratégia para fortalecimento do controle social e da gestão democrática e participativa do SUS. [Internet]. 2010 [acesso 2013 Nov 3]. Disponível em: http://www.saude.ba.gov.br/dgtes/index.php?option=com content \&view $=$ article\&id $=290 \&$ catid $=116 \&$ Itemid $=196$

17. Dantas Neto PF. Mudança política na Bahia: circulação, competição ou pluralismo de elites? [Internet]. Observatório Social do Nordeste. Fundação Joaquim Nabuco; 2009 [acesso 2013 Nov 3]. Disponível em: http://www.fundaj.gov.br/geral/observanordeste/ ixedicao/OBSERVANORDESTE_IX_Edicao_texto_BA_rev.pdf

18. Parada TCS. MobilizaSUS: uma aproximação à experiência baiana. In: Parada TCS. MobilizaSUS na Bahia: emergência, desenvolvimento e contradições do cotidiano institucional [dissertação]. Salvador (BA): Instituto de Saúde Coletiva, Universidade Federal da Bahia; 2010. p. 15-53.

19. Bianchi A. O laboratório de Gramsci: filosofia, história e política. São Paulo: Alameda; 2008.

20. Gruppi L. Tudo começou com Maquiavel: as concepções de Estado em Marx, Engels, Lênin e Gramsci. Porto Alegre: L\&PM Editores; 1980.

21. Portelli H. Gramsci e o bloco histórico. Rio de Janeiro: Paz e Terra; 1977.

22. Paim JS. Reforma Sanitária Brasileira: contribuição para a compreensão e crítica. Salvador: EDUFBA; 2008.

23. Behring ER. Fundamentos de política social. In: Mota AE, Bravo MIS, Uchoa R, Nogueira V, Marsiglia R, Gomes $L$, et al., organizadores. Serviço social e saúde: formação e trabalho profissional. São Paulo: OPAS, OMS, Ministério da Saúde; 2006. p. 13-49.

24. Fleury SM, organizadora. Reflexões teóricas sobre democracia e reforma sanitária. 3a ed. São Paulo: Cortez; 2006. p. 17-46.

25. Gerschman S. Formulação de Políticas Sociais. In: Fleury SM, organizadora. Reforma Sanitária: em busca de uma teoria. 3a ed. São Paulo: Cortez; 2006. p.119-38.

26. Santos EM. E agora: somos marqueteiros de cyborgues eternos? In: Arouca S. O dilema preventivista: contribuição para a compreensão e crítica da medicina preventiva. São Paulo: Ed. Unesp; 2003. p. 203-8.

27. Escorel S. Reviravolta na Saúde: origem e articulação do movimento sanitário. Rio de Janeiro: Fiocruz; 1998.

28. Anais da 8a Conferência Nacional de Saúde; 1986 Mar 17-21; Brasília, Brasil [Internet]. Brasília Centro de Documentação do Ministério da Saúde; 1987 [acesso 2014 Mar 5]. Disponível em: http://conselho.saude.gov.br/biblioteca/Relatorios/relatorio_8.pdf

29. Fleury SM. Para uma teoria do movimento sanitário. In: Arouca S, organizador. O dilema preventivista: contribuição para a compreensão e crítica da medicina preventiva. São Paulo: Ed. Unesp; 2003. p. 243-8.

30. Paim JS. A Reforma Sanitária Brasileira e o Sistema Único de Saúde: dialogando com hipóteses concorrentes. Physis. 2008;18(4):625-44.

31. Oliveira JA. A Saúde Pública hoje: notas para um debate sobre a conjuntura em saúde e a situação da ENSP ao seu interior. Cad Saude Publica. 1988;4(3):326-33.

32. Goulart FA. Esculpindo o SUS a golpes de portaria...: considerações sobre o processo de formulação das NOBs. Cienc Saude Colet. 2001;6(2):292-300. 
33. Testa M. Pensar en Salud. Buenos Aires: Lugar Editorial; 1993.

34. Fleury SM. Reforma Sanitária Brasileira: dilemas entre o instituinte e o instituído. Cienc Saude Colet. 2009;14(3):743-52.

35. Semeraro G. Da sociedade de massa à sociedade civil: a concepção da subjetividade em Gramsci. Educ Soc.1999; 20(66):65-83.

36. Scherer-Warren I. Redes de movimentos sociais. 3a ed. São Paulo: Loyola; 2005.

37. Gohn MG. Movimentos sociais no início de século XXI: antigos e novos atores sociais. 3a ed. Petrópolis: Vozes; 2007

38. Pedrosa JIS. Educação Popular no Ministério da Saúde: identificando espaços e referências. In: Ministério da Saúde, Secretaria de Gestão Estratégica e Participativa, Departamento de Apoio à Gestão Participativa, organizadores. Caderno de Educação Popular em Saúde. Brasília (DF): Ministério da Saúde; 2007. p. 12-7.

39. Vasconcelos EM. Educação Popular: instrumento de gestão participativa dos serviços de saúde. In: Ministério da Saúde, Secretaria de Gestão Estratégica e Participativa, Departamento de Apoio à Gestão Participativa, organizadores. Caderno de Educação Popular em Saúde. Brasília (DF): Ministério da Saúde; 2007. p. 18-29.

40. Lucchesi G. Burocracia e política de saúde: arena ou ator? In: Fleury SM, organizadora. Reforma Sanitária: em busca de uma teoria. 3a ed. São Paulo: Cortez; 2006. p. 157-79.

41. Milani CRS. Políticas públicas locais e participação na Bahia: o dilema gestão versus política. Sociologias [Internet]. 2006 [acesso 2014 Mar 5]; (16):180-214. Disponível em: http://www.scielo.br/scielo.php?script=sci_arttext\&pid=S1517-45222006000200008\&ln $\mathrm{g}=$ pt\&nrm=iso. http://dx.doi.org/10.1590/S1517-45222006000200008

42. Pinheiro IO. A política na Bahia: atrasos e personalismos. Ideação (Feira de Santana). 1999;(4):49-78.

43. Dantas Neto PF. "Surf" nas ondas do tempo: do Carlismo Histórico ao Carlismo pósCarlista. Cad CRH. 2003;(39):213-55.

44. Paim JS. Formulação de políticas de saúde: comunicação em vigilância sanitária. In: Costa EC, Rangel ML, organizadores. Comunicação em Vigilância Sanitária: princípios e diretrizes para uma política. Salvador: EDUFBA; 2007. p. 41-55.

45. Paim JS. Desafios para a saúde coletiva no século XXI. Salvador: EDUFBA; 2006. 
Silva TPC, Teixeira CFS. Significado político del MobilizaSUS en Bahia dentro de la perspectiva de Gramsci, a través de la reforma sanitaria brasileña. Interface (Botucatu). 2014; 18 Supl 2:1283-1298.

Considerando la experiencia del proyecto MobilizaSUS en Bahia dentro del debate acerca de los límites y posibilidades de la participación popular en la salud, definimos como objetivo discutir el significado político de su desarrollo. Esta discusión se dio a la luz de la Reforma Sanitaria Brasileña, articulada a partir de las categorías gramscianas. Podemos inferir que el proyecto MobilizaSUS posee características que permitirían colocarlo al lado de la contra-hegemonía en el sector de la salud. Sin embargo, hay límites para su afirmación como proyecto contrahegemónico, relacionados principalmente con su origen institucional, aproximándose más a la idea de representar poros permeables a la contrahegemonía en la superestructura, en función de su método de articular sujetos de la antítesis en una praxis histórica en Bahia.

Palabras clave: Políticas de salud. Participación social. Cambio social. 
